\title{
ROLE OF HRIS AND KNOWLEDGE SHARING BEHAVIOUR TOWARDS INNOVATION CAPABILITY: MODERATING EFFECT OF ORGANIZATIONAL CITIZENSHIP BEHAVIOUR
}

\author{
Madiha Shaikh', Mohsin Diwan², and Ramesh Kumar ${ }^{3}$
}

\begin{abstract}
The objective of the study was to examine the impact of HRIS usage and knowledge sharing behaviour on the innovation capability of banking sector employees. The study also investigated the moderating role of organizational citizenship behaviour on the effect of HRIS usage and knowledge sharing behaviour on innovation capability. The Resource-Based View and Organizational Citizenship Behaviour theories are applied in this research. This study is based on a quantitative approach for data collection and the data was examined using a correlational research design. The target population of this study is based on the employees of private banks of Karachi, Pakistan. The sample size was 187 responses which were analyzed using linear regression. The results showed that human resource information system usage has a positive and significant effect on employee's innovation capacity. Similarly, knowledgesharing behaviour was also found positive but had an insignificant effect on employee's innovation capacity. The results also demonstrated that organizational citizenship behaviour has a positive and significant moderated effect on the relationship of human resource information systems and employee's innovation capacity and in the relationship between knowledge-sharing behaviour and employee's innovation capacity. This study provides a model to management leaders and practitioners who can look into employees' creative capabilities and leverage them. The study suggests that certain actions need to be implemented by top management to foster a positive attitude towards employees' innovation capacity through proper HRIS usage and knowledge-sharing behaviour over the span of time. Lastly, implications and avenues for future research are also suggested at the end of the paper.
\end{abstract}

Keywords: HRIS Usage; Knowledge-Sharing Behaviour; Organizational Citizenship Behaviour; Employees' Innovation Capacity.

\footnotetext{
${ }^{1}$ Faculty of Management Sciences, SZABIST, Karachi, Pakistan. Email: madiha@szabist.pk

${ }^{2}$ Faculty of Management Sciences, SZABIST, Karachi, Pakistan. Email: mohsindiwan@hotmail.com

${ }^{3}$ Faculty of Management Sciences, SZABIST, Karachi, Pakistan. Email: rameshkumaranu2012@gmail.com
} 


\section{INTRODUCTION}

In the current knowledge economy era, the aspect of mastering technology, capital access, and success in previous tasks could not be enough for a company to win or be able to compete in the world (Harjanti \& Noerchoidah, 2017). Now, the aspect of knowledge is becoming the base for a competitive organization, and the ideas that focus on products, as well as the application of these ideas on the product, are considered as daily tasks or activities for developing the economy (Hadad, 2017; Moussa \& El Arbi, 2020). The study provides an evaluation of the capacity of individual innovation in the literature of information systems. HRIS researchers have aimed to establish individual innovation in different and sometimes conflicting directions (Magableh \& AlTarawneh, 2021). In addition, the major asset or strength of an organization was deemed to be in intellectual capital that has been connected with every individual and was known as an intangible asset (Agostini et al., 2017). However, in the presence of intellectual capital, the information could be changed into knowledge for individuals in the organization (Allameh et al., 2017).

The application of innovation is complex and is one of the main reasons that many of the weaker competitive performances become difficult to manage in absence of innovation. Moreover, employees go through many difficulties to overcome barriers and they sometimes resist innovation (Ologbo et al., 2015). The only constant thing is changing dynamics for the firms adopting the operations technology. To be able to meet the demand of the changes, information systems help in structuring and organizing the processes in the firm. The human resource (HR) have started to show higher requirements for supporting technologies. Hence, a significant amount of business firms are investing in HRIS in recent years (Brandon-Jones \& Kauppi, 2018). The human resource information system collects information and operating data needed for structuring problems in HR, which includes human resource management, placement and recruitment, training and development, management of wages, relations in the industry, safety and health of the firm, career development and planning, social services management, management and organization of development, management of performance, relationship with the trade unions, and transfer of information to the needed entities of information of this kind (Kavanagh \& Johnson, 2017; Magableh \& Al-Tarawneh, 2021).

The procedures of keeping in context to human resources in the digital age have significant advantages regarding the costs, effectiveness, efficiency as well as competitive advantage (Bayraktaroğlu\& Atay, 2016). Management of knowledge can enable the firms to obtain, operate, organize, distribute and apply the knowledge when it is needed (Zhang et al., 2012). It provides significant benefits to firms to monitor huge amounts of information for the HRIS utilization, as 
this system helps and allows the firm to control and use the human resource data for effectiveness and better results (Bondarouk et al., 2017). The potential of transforming is found in combining the robust human resource information among various departments and units. Hence, firms need to organize all the human resource operations and logically complete them to allow strategic global implementation.

Similarly, the sharing of knowledge was deemed an essential factor in knowledge management practice that could help in creating, sustaining and harvesting the business processes, so that the members of the organization collaborate and mutually help to finish tasks; solve problems and develop new ideas (Rahmat Ullah Shah \& Mahmood, 2013). Moreover, the knowledge sharing success could help the organizations in developing the innovative capability to be responsive to sudden changes in the environment (Abubakar et al., 2019).

Not being willing to change is also one of the biggest challenges. On the other hand, some firms hamper innovation in some ways. Hence, it is an issue to push the employees to achieve breakthroughs in the development of innovation (Saripin \& Kassim, 2019). Many firms and employees have the knowledge yet they do not share it with colleagues or their managers, but is rarely shared among fellow entrepreneurs which result in innovation being suppressed due to the lack of knowledge sharing. Many research studies have investigated the role of knowledge sharing behaviour to improve employees' innovation capabilities (Constance et al., 2019; Yang et al., 2018). Some studies have examined the effect of organizational citizenship behaviour on employees' innovation capabilities (Suwanti et al., 2018). Additionally, Kaygusuz (2016) investigated the effects of HRIS usage on employee performance with the intervention of organizational efficiency but all those and other studies did not examine the moderation of organization citizenship behaviour and knowledge sharing behaviour as an independent variable.

Considering all the above limitations and gaps, the current study is an attempt to examine the effects of HRIS usage and knowledge sharing behaviour on employees' innovation capability. The study also investigated the moderating role of organizational citizenship behaviour on the effect of HRIS usage and knowledge sharing behaviour on innovation capability. Further, this study will be a considerable endeavour in knowledge-sharing stimulation in the workplace, particularly in large organizations and study generalizations will not be limited to Pakistan but will be applicable in the worldwide context. Moreover, HRIS and its effect on the aspects of innovation capability of an employee and the moderation of OCB will give a clear picture that how companies may be successful and achieve competitive edge if they focus on employees' knowledge sharing and the role of HRIS altogether. 


\section{LITERATURE REVIEW}

\section{Resource-Based View Theory}

The theory of resource-based view (RBV) has arisen as an essential theory in the field of strategic management. It overlooks the acts of business strategies and business capabilities as the key resource for competitive advantage in the organization (Akio, 2005). The theory of resource-based originates from the concept that the internal resource of organizations are the mainsource of competitive advantage in contrast to their standing with external dynamics mentioning that the competitive advantage is related to opportunities and threats that are owned by the organization (Barney, 1995). The theory of resource-based view explains that specific resources possessed and utilized by the organizations own the ability and capacity of generating increased performance and provide competitive advantage (Bromiley \& Rau, 2016). The RBV is one of the highly used theoretical models in management studies (Runyan et al., 2006). Being able to understand the origins of the competitive advantage that sustains is constantly being evaluated in the strategic management field (Bacq \& Eddleston, 2018). Hence, this study will adopt the resource-based view theory as a theoretical framework where the human resource of a firm will be regarded as the source of competitive advantage.

\section{Organizational Citizenship Behaviour Theory}

According to Bantha \& Sahni (2021) the Organizational Citizenship Behaviour theory, also known as OBC, was introduced by Organ in the late 1980s. The theory of organizational citizenship behaviour as explained by Organ (1988) as a comprehensive view of a firm however, it is naturally made by employees and is not involved in the conventional reward system of the firm. It is a "free will" behaviour of employees, yet it is not provided in the role of the employees or included in their job description (Bogler \& Somech, 2019; Khan et al., 2021). The OCB is a transparent contract of employment among the employees and the firm and can be regarded as a personal choice. As explained, the OCB can help improve the performance of the firm, while numerous scholars providing different viewpoints that how it can enhance organizational performance (Newman et al., 2017). OCB impacts the firm performance in seven areas, by improving employee efficiency, releasing resources for work productivity, decreasing scarcity of resources to maintain adequate functionality, aid in coordinating within and among the workgroups, improve the firm ability to attract and retaining of talent, improve the firm stability and making firm in better adapt to changes in business dynamics. Hence, organizational citizenship behaviour theory is adopted for this study. 


\section{HRIS and Employee Innovation Capabilities}

Based on a systematic review of practices, laws, and scientific literature, Matimbwa \& Masue (2019) reviewed the process, new developments, and challenges facing the Tanzanian HRIS takeover. Given HRIS's prominence and positive improvements to successful public-sector HRM, the study documented five major challenges relevant to the usage of HRIS, including; (i) unreliable financial ability to acquire, upgrade and retain HRIS; (ii) insufficient ICT and HRIS skills among HRM workers; (iii) Insufficient organization of government bureaucracy in the execution of its constitutional responsibilities; (iv) Internet connectivity uncertainty; and (v) inadequate top management help.

Moussa and El Arbi (2020) focused on the analysis of the effect on employee creativity capabilities of the use of HRIS in the human resource department. A research model was established and relevant results were reviewed in Tunisian companies' human resource departments with 42 respondents. It was observed that an effective engagement of workers enhances the interaction between the use of HRIS and the potential for individual creativity. In addition, the more effectively workers interact with their company, the more optimistic and remarkable is the HRIS effect on the actual creative actions of HR employees. Valcik, Sabharwal \& Benavides (2021) stated that HRIS is one of the organizations most important elements, but a vast number of human resources are difficult to manage (Azam et al. 2019), particularly in large companies. Companies have continued to leverage these services to this purpose by taking advantage of the technology and the internet. Mauro and Borges-Andrade (2020) pointed to determine applicable views to attain the benefits of the creative and inventive ability of the system of human resource information (HRIS). Vital views about the efficient acceptance of HRIS were reported, like features of the system, process of execution and model of HR. Gibson, Gibson, and Webster (2021) aimed to resolve the gap of disruptions and disturbance in human origins technology and their impacts and consequences towards the management of the human resource in organizations of healthcare. Consideration over the community and makers of the policy about the present and upcoming shortage of staff was studied extensively. But, some of the present researches that discussed technology or its effect on the tasks have emphasized health-related organizations. To sum up, HR professionals in healthcare organizations use HRIS accountably and try to create a balance between the innovation factors, creativity and efficacy. Accordingly, with the above literature we propose the following hypothesis:

H1A: HRIS usage has a significant impact on the innovation capability of firms. 


\section{Knowledge Sharing Behaviour and Employee Innovation Capabilities}

Riana et al. (2019) propositioned to build creativity in the Ikat weaving industry in Bali through knowledge sharing and absorptive power. This work was carried out using both qualitative and quantitative methods. Outcomes of the study indicated that the information acquired from external resources was expected to fill in the organization's available information; the exchange of information was found to be more valuable and successful in promoting creativity. Although sharing knowledge did not dramatically affect innovation enhancement, sharing knowledge was still important to improve the awareness of stakeholders about the business in general and the work tasks in particular. The creativity of leaders was an essential element in acquiring and gathering information from external resources because the exchange of expertise had a significant influence on innovation through absorptive capacity. It was recommended that awareness and studying unique knowledge should be preserved to improve workers' knowledge and understanding of new external experiences (Halisah et al., 2021).

Asurakkody and Hee (2020) indicated the connection between the exchange of knowledge, information and creative work by evaluation of self-leadership and management playing the role of mediator. The finding of the study showed a decisive and notable relationship between knowledge exchanging and creative work behaviour.

Similarly, Afsar et al. (2019) aimed to investigate the influence of transformative management towards the creative work of employees' through job crafting. Additionally, the study investigated the moderating influence of knowledge sharing behaviour in the association between transformative management and creative work behaviour. The target population of the study was the supervisors and the employees working in the four and five-star hotels in the hospitality industry in Pakistan. The finding of the research showed that the job crafting behaviour (enhancing structural job origins, enhancing social origins and enhancing challenges of the job) mediated the influence of transformative management towards the creative work behaviour of employees. Furthermore, knowledge sharing played a moderating role in the connection between transformative management and creative work behaviour.

H2A: Knowledge sharing behaviour significantly impacts innovation capability.

\section{The Moderating Role of Organizational Citizenship Behaviour (OCB)}

Leadership affects the performance of employees relating to their innovative work conduct, and 
this phenomenon is widely identified in higher education leadership studies, especially in Pakistan. Razzak et al. (2019) demonstrated the impact of leadership styles on creative job activity among the Heads of Departments (HODs) in higher education institutions (HEIs). Khan et al. (2020) mediated and moderated the functions in the same relationship with corporate culture and organizational citizenship behaviour. The statistical study showed a significant positive impact of leadership styles on workers' innovative work behaviour, demonstrating the mediating and moderating influence of organizational culture and OCB on such a partnership. The study has thus carried numerous ramifications in both theoretical and practical fields of prior research, and its reach may also be extended to another sense, geographically or institutionally.

Concerning the study objective, Constance et al. (2019) provided an insight into the interaction between supervisory accountability, corporate citizenship behaviour OCB) and constructive actions using the tacit knowledge sharing approach in mediation. Data were obtained from a Malaysian public teaching hospital from a group of 339 nurses. The findings offered justification for considering certain explanations for the causal effect since they found statistically meaningful relationships. For the indirect effect, it was assumed after the mediation research protocol that the implicit exchange of information partly mediated the interaction as both the direct and indirect effects were important. This research offered a new viewpoint on the mediating impact of implicit information sharing in predicting individual factors (supervisory justice and OCB) for the innovative work performance of nurses.

Naeem et al. (2019) intended to investigate the mediating influence of emotive, inspirational commitment, trust and affect-based trust on the association between activities belonging to the human resource management and sharing knowledge behaviour of faculty members. The outcomes of the research showed that intermediating variables like emotive commitment and affect-based trust also validated and played a mediating role in human resource management activities and knowledge sharing behaviour of faculty. The findings also validated the decisive and major influence of human resource management activities over the knowledge sharing behaviour of faculty.

H3A: Does organizational citizenship behaviour moderate the relationship between HRIS usage and employees' innovation capability?

H4A: Does organizational citizenship behaviour moderate the relationship between knowledge sharing behaviour and employees' innovation capability? 
Figure 1. Conceptual Framework

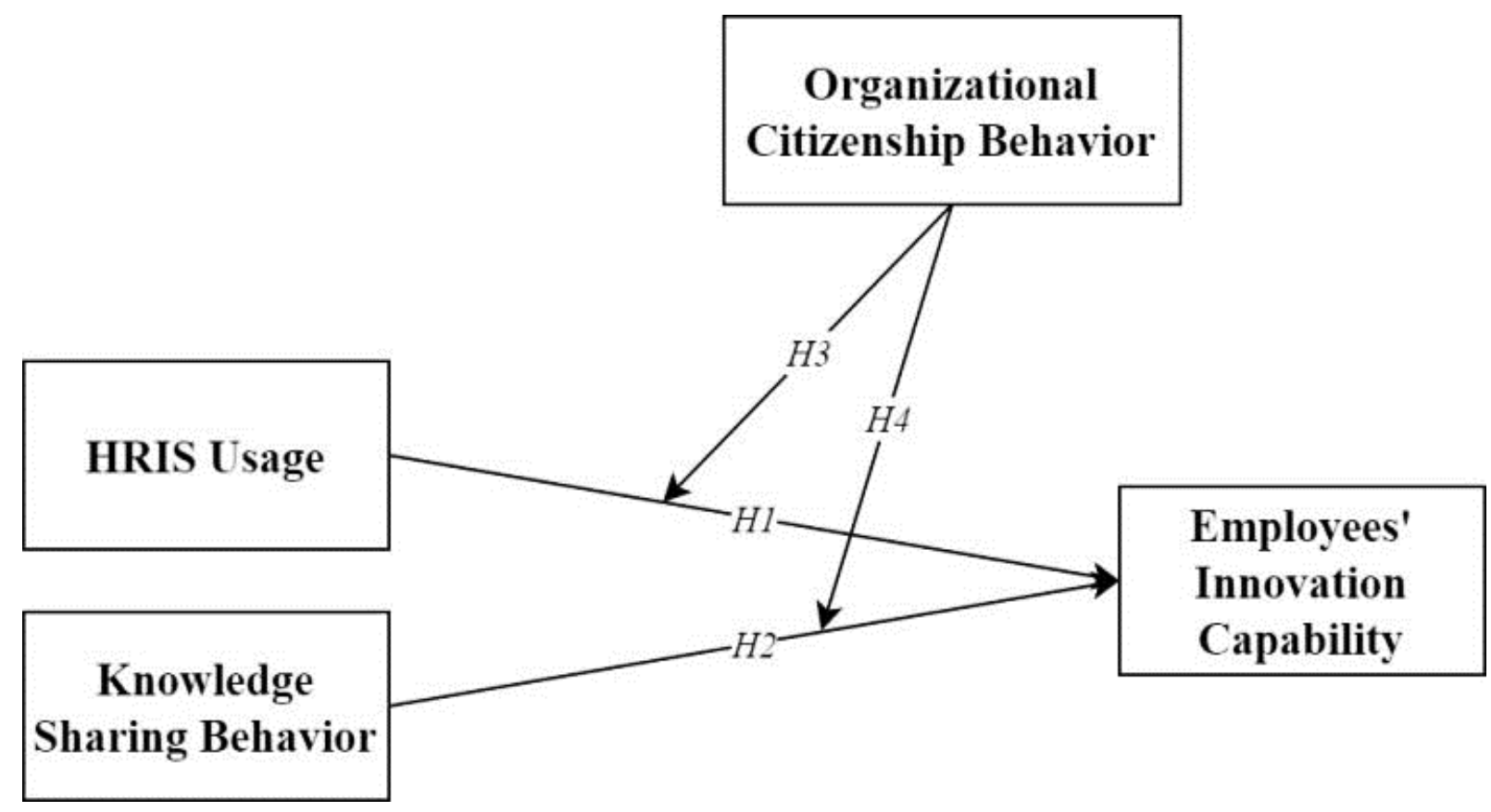

Source: Author's Contribution

\section{RESEARCH METHODOLOGY}

It is the systematic approach to focus on examining the objective measurements and analyze the statistical data using different computational techniques (Neuman, 2013). The current study has adopted a quantitative method for data collection. The rationale for selecting this approach is that it helps in emphasizing the logical stance regarding the research objective and provides an effective way to collect a large amount of data within no time. It also helped the researcher to develop differentiation in various groups of population and derived few preference trends as well. The current study aimed to use a deductive approach. The reason for selecting the deductive approach was that it allowed the researcher to reasoning and debating as well. The main reason was that it helped in making conclusions and restrained the presence of errors as well. Similarly, this has employed an explanatory investigation. The basic concept behind explanatory research is that it is conducted for such problems that have not been studied properly or required some more investigation with priorities (Flick, 2015). Thus, the main rationale for using explanatory investigation in this study was to aid in enhancing the knowledge aspect and understanding regarding some particular research objective or problem. Furthermore, the study design adopted in this study is correlational in nature. As correlational design provides the effect of one variable onto the other and examines how it affects that other variable (Leary, 2004), the correlational design allowed the researcher to examine variables more efficiently. 


\section{Sampling Design}

The banking sector is one of the soaring sectors in Pakistan. More than thirty different banks are operating in Pakistan, including public sector and private sector banks. Moreover, there are also fifteen Islamic banks including six full-fledged Islamic banks. Hence, the target population of the current study was the private banks from the banking sector of Karachi, Pakistan. The data was collected from the employees of the banks.

For sampling technique, the current study has used the $50+8 \mathrm{~K}$ formula given by Tabachnick et al. (2007) for sample size where $K$ was the total number of variables presented in the model framework. As the number of variables for this study was four, therefore the minimum sample size was estimated to be a minimum of eighty-two (82) required responses. Therefore, the study aimed to collect 150-200 responses from the sample population. Moreover, the current research has adopted purposive sampling for selecting the participants. The reason for selecting this technique was that it allowed the researcher to collect a large amount of information from the dispersed data. Similarly, another reason was that it helped the researcher to focus on specific characteristics of people. To gather the data, survey questionnaires were distributed. The questionnaires were based on a five-point Likert scale. Furthermore, for data analysis, this study has employed descriptive statistics using frequency analysis for providing demographics of respondents and summarizing the frequency of their data. The reliability of the instrument of data collection was tested using Cronbach's alpha. Lastly, multiple regression analysis was conducted to analyze the data and to infer statistical results.

\section{RESULTS}

Table 1. Demographic Profile

\begin{tabular}{llll}
\hline & & Frequency & Percent \\
\hline Gender & Male & 164 & 87.7 \\
& Female & 23 & 12.3 \\
Age Group & $20-25$ & 27 & 14.4 \\
& $26-35$ & 45 & 24.1 \\
& $36-45$ & 115 & 61.5 \\
Education & Undergraduate & 54 & 28.9 \\
& Graduate & 87 & 46.5 \\
& Post-Graduate & 46 & 24.6 \\
Experience & Less than 1 year & 50 & 26.7 \\
& 1 to 5 years & 69 & 36.9 \\
& 5 to 10 years & 68 & 36.4 \\
Bank Name & Bank Al-Habib & 18 & 9.6 \\
& Muslim Commercial Bank & 85 & 45.5 \\
& Faisal Bank Limited & 17 & 9.1 \\
& United Bank Limited & 50 & 26.7 \\
\hline
\end{tabular}

Source: Study Analysis 


\section{Measurement Model}

Table 2. Factor Loadings

\begin{tabular}{|c|c|c|c|c|}
\hline & ECI & HU & KSB & OCB \\
\hline EIC1 & 0.925 & & & \\
\hline EIC2 & 0.915 & & & \\
\hline HU2 & & 0.844 & & \\
\hline HU4 & & 0.833 & & \\
\hline HU5 & & 0.694 & & \\
\hline HU6 & & 0.760 & & \\
\hline HU7 & & 0.816 & & \\
\hline KSB1 & & & 0.905 & \\
\hline KSB2 & & & 0.932 & \\
\hline KSB3 & & & 0.879 & \\
\hline KSB4 & & & 0.933 & \\
\hline OCB4 & & & & 0.862 \\
\hline OCB5 & & & & 0.909 \\
\hline OCB6 & & & & 0.938 \\
\hline
\end{tabular}

Following the recommendations given for factor loading by Hair et al., (2014) the above table (2) refers that the values that are higher than 0.70 are highly acceptable and values less than 0.40 are not acceptable. However, values that are in a range between 0.40 and 0.70 are also acceptable based on convergent validity (Hair et al., 2016). The highest value for employees' innovation capacity is 0.925 and the lowest is 0.915 . The highest value for HRIS usage is 0.844 and the lowest value is 0.694 . The highest value of knowledge-sharing behaviour is 0.933 and the lowest value is 0.879 . Whereas, the highest value for organizational citizenship behaviour is 0.938 and the lowest value is 0.862 . Hence, this table has successfully achieved outer loadings.

\section{Construct Reliability and Validity}

Table 3. Construct Reliability and Validity

\begin{tabular}{lccc}
\hline & $\begin{array}{c}\text { Cronbach's } \\
\text { Alpha }\end{array}$ & $\begin{array}{c}\text { Composite } \\
\text { Reliability }\end{array}$ & $\begin{array}{c}\text { Average Variance } \\
\text { Extracted (AVE) }\end{array}$ \\
\hline Employees' Innovation Capacity & 0.819 & 0.917 & 0.846 \\
HRIS Usage & 0.855 & 0.893 & 0.626 \\
Knowledge-Sharing Behaviour & 0.933 & 0.952 & 0.833 \\
Organizational Citizenship Behaviour & 0.888 & 0.930 & 0.816 \\
\hline
\end{tabular}

Source: Study Analysis

The above table has a recommended threshold that values of CR should be higher than 0.70 and values of AVE should be higher than 0.50 (Hair et al., 2011). The above table has accomplished this recommendation and hence reliability is validated. 


\section{Discriminant Validity}

Table 4. Fornell and Larcker Criterion

\begin{tabular}{lllll}
\hline & ECI & HU & KSB & OCB \\
\hline Employees' Innovation Capacity & 0.920 & & & \\
HRIS Usage & 0.664 & 0.791 & & \\
Knowledge-Sharing Behaviour & -0.547 & -0.767 & 0.912 & \\
Organizational Citizenship Behaviour & 0.814 & 0.685 & -0.678 & 0.904
\end{tabular}

\section{Source: Study Analysis}

The recommended threshold for the above table is that all bold and diagonal values must be higher in their constructs as compared to values in others (Fornell \& Larcker, 1981). Therefore, this table has achieved this recommendation and helped in achieving discriminant validity via using Fornell and Larcker criterion.

Similarly, the cross-loadings in table 5 below suggest that the values must be higher in their constructs in a horizontal manner than their values in other constructs (Hair et al., 2014). Hence, discriminant validity has been achieved using cross-loadings.

Table 5. Cross Loadings

\begin{tabular}{ccccc}
\hline & ECI & HU & KSB & OCB \\
\hline EIC1 & $\mathbf{0 . 9 2 5}$ & 0.582 & -0.417 & 0.766 \\
EIC2 & $\mathbf{0 . 9 1 5}$ & 0.641 & -0.595 & 0.731 \\
HU2 & 0.433 & $\mathbf{0 . 8 4 4}$ & -0.773 & 0.618 \\
HU4 & 0.411 & $\mathbf{0 . 8 3 3}$ & -0.770 & 0.543 \\
HU5 & 0.334 & $\mathbf{0 . 6 9 4}$ & -0.485 & 0.366 \\
HU6 & 0.705 & $\mathbf{0 . 7 6 0}$ & -0.389 & 0.471 \\
HU7 & 0.566 & $\mathbf{0 . 8 1 6}$ & -0.705 & 0.676 \\
KSB1 & -0.370 & -0.600 & $\mathbf{0 . 9 0 5}$ & -0.546 \\
KSB2 & -0.551 & -0.672 & $\mathbf{0 . 9 3 2}$ & -0.736 \\
KSB3 & -0.413 & -0.809 & $\mathbf{0 . 8 7 9}$ & -0.498 \\
KSB4 & -0.597 & -0.721 & $\mathbf{0 . 9 3 3}$ & -0.647 \\
OCB4 & 0.625 & 0.559 & -0.438 & $\mathbf{0 . 8 6 2}$ \\
OCB5 & 0.771 & 0.594 & -0.680 & $\mathbf{0 . 9 0 9}$ \\
OCB6 & 0.795 & 0.696 & -0.690 & $\mathbf{0 . 9 3 8}$ \\
\hline
\end{tabular}

Source: Study Analysis

\section{Structural Model}

We have used the PLS bootstrapping 5000 sample technique to test the hypotheses in Smart PLS3. The below figure depicts the relationship between the independent, moderating and dependent variables; the results of which are listed in Tables 6 and 7. 
Figure 2. PLS Bootstrapping Model

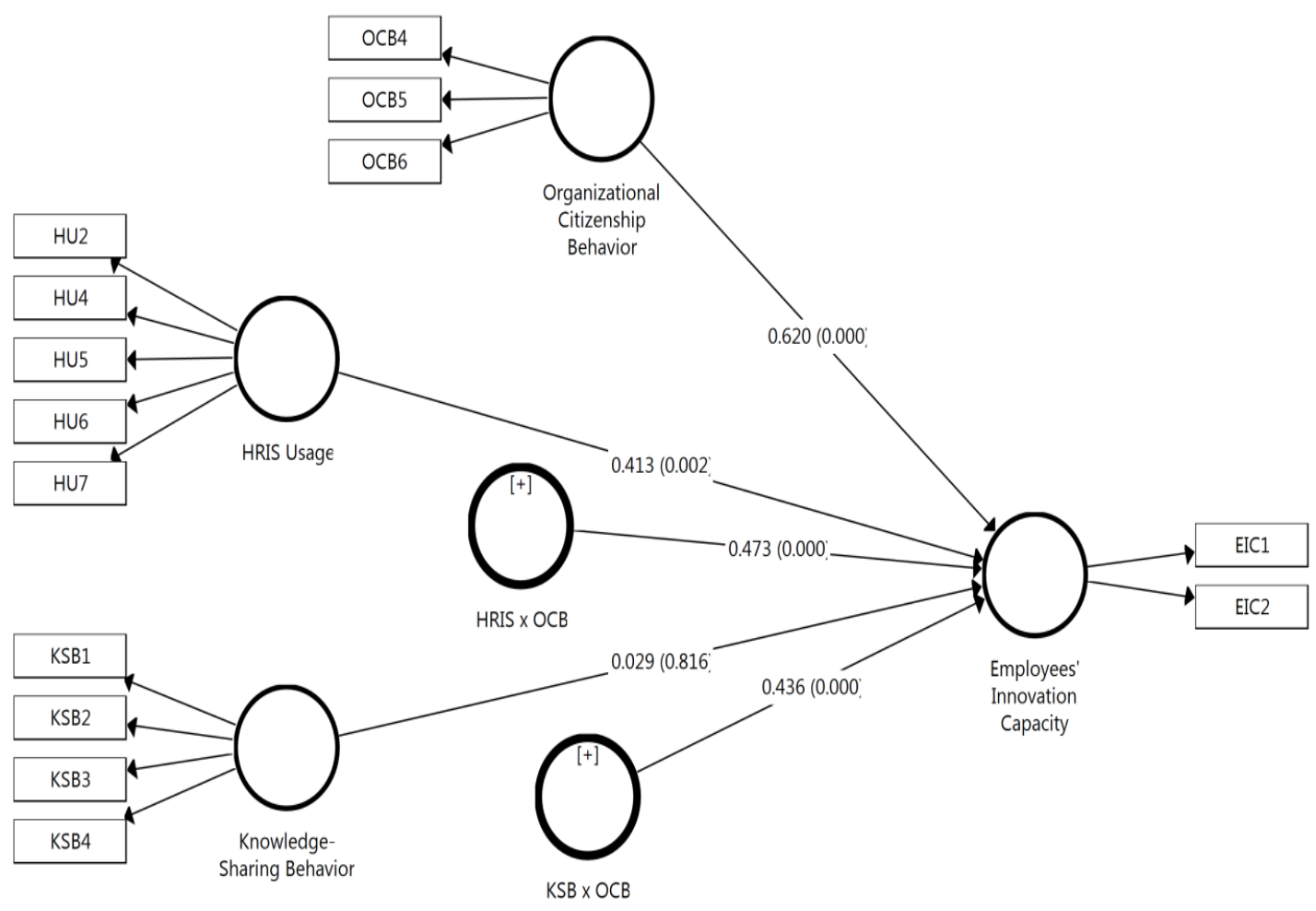

Source: Study Analysis

Table 6. Path Analysis using PLS-SEM

\begin{tabular}{|c|c|c|c|c|}
\hline & Estimate & S.D. & T-Stats & Prob. \\
\hline HRIS Usage -> Employees' Innovation Capacity & 0.413 & 0.131 & 3.148 & 0.002 \\
\hline $\begin{array}{l}\text { Knowledge-Sharing Behaviour -> Employees' } \\
\text { Innovation Capacity }\end{array}$ & 0.029 & 0.124 & 0.232 & 0.816 \\
\hline $\begin{array}{l}\text { Organizational Citizenship Behaviour -> Employees' } \\
\text { Innovation Capacity }\end{array}$ & 0.620 & 0.043 & 14.516 & 0.000 \\
\hline
\end{tabular}

Source: Study Analysis

The above table 6 . shows that hypothesis 1 examining human resource information system usage $(0.413, \mathrm{p}<0.10)$ has a positive and significant effect on employee's innovation capacity. Hypothesis 2 examining knowledge-sharing behaviour $(0.029, \mathrm{p}>0.10)$ has a positive but insignificant effect on employee's innovation behaviour. The organizational citizenship behaviour $(0.620, \mathrm{p}<0.10)$ has a positive and significant effect on employee's innovation capacity.

Table 7. Moderation Analysis

\begin{tabular}{lllll}
\hline & Estimate & S.D. & T-Stats & Prob. \\
\hline HRIS x OCB -> Employees' Innovation Capacity & 0.473 & 0.091 & 5.184 & 0.000 \\
KSB x OCB -> Employees' Innovation Capacity & 0.436 & 0.085 & 5.141 & 0.000 \\
\hline
\end{tabular}

Source: Study Analysis 
The above table shows that organizational citizenship behaviour $(0.473, \mathrm{p}<0.10)$ has a positive and significant moderated effect with the relationship of human resource information system usage and employee's innovation capacity. Also, organizational citizenship behaviour (0.436, $\mathrm{p}<0.10$ ) has a positive and significant moderated effect on the relationship between knowledgesharing behaviour and employee's innovation capacity.

Table 8. Predictive Relevance

\begin{tabular}{cccc}
\hline & R Square & R Square Adjusted & Q Square \\
\hline Employees' Innovation Capacity & 0.745 & 0.738 & 0.600 \\
\hline Source: Study Analysis & & &
\end{tabular}

The above table shows that employee's innovation capacity has been predicted up to 74.5 percent $(\mathrm{R}-\mathrm{Square}=0.745)$ while the value of $\mathrm{Q}$ square is greater than absolute zero.

\section{CONCLUSION AND DISCUSSION}

The results of this study have been quite beneficial in understanding the aspect of employees' innovation capacity. The relationship between human resource information system usage (HRIS) and employee's innovation capacity is positive and significant. This result is aligned with the findings of Ahmer (2013) and Moussa \& El Arbi (2020). The use of HRIS enables the employees to manage their schedule and tasks with more efficient behaviour and eventually increase their working and innovation. Also, this result was related to the findings of Barišić et al. (2018); Khashman \& Khashman (2016); Scupola \& Pollich (2019) that specified that an increase in using HRIS could help organizations to increase their effectiveness and efficiency and this positively influences the employee's attitude and their innovation.

The second relationship between knowledge-sharing behaviour (KSB) and employee's innovation capacity was found positive but insignificant. This result is in line with Liao et al., (2007) that reveal that an increase in KSB does not help in increasing their innovative capacity. The reason for getting this result might be that when exchanging information, it was just a concept and not concrete knowledge or matter that does not provide any help in increasing their innovation. So, knowledge should be reprocessed with higher authority for better outcomes. Also, Qamari et al. (2019) stated that an increase in presence of knowledge sharing does not increase innovation and this finding has been not in line with previous researches. This finding means that when employees were sharing information either it was not relevant regarding the task or not conclusive enough to increase their innovative capacity.

The third relationship between organizational citizenship behaviour (OCB) and employee's 
innovation capacity was found positive and significant. This result is in line with Yan and Yan (2013) that OCB helps in increasing the innovation of employees by providing a helping and understanding environment in the organization. Also, (Constance et al., 2019; Hadi \& Saerang, 2020) revealed that OCB and innovation behaviour of employees are positively related. This proposes that when employees are properly communicating with each other and committing fully within the organization then it increases their innovation capacity.

The fourth result validated that OCB has a positive and significant moderation effect towards HRIS usage and employee's innovation capacity. This result is in line with Khan et al. (2020) that proposed the presence of OCB can significantly influence the innovation capacity and increase their working aspect as well. Yoon (2009) stated that when employees were engaged in effective OCB it positively increases their work and innovative behaviour as well.

The fifth result shows that OCB has a positive and significant moderation effect on KSB and employee's innovation capacity. This result is in line with Nguyen \& Malik (2020) that refers that the presence of OCB in the knowledge-sharing environment tends to increase the innovation capacity of employees. The reason was that employee tends to do extra job or tasks that increase their innovation. Also, this result is in relation with (Constance et al., 2019; Siddiqui et al., 2019) that when employees engage in KSB with the moderation of OCB then their innovation capacity also increases because it makes to do work other than their job description and also in a collaborative environment that increases the organization's performance as a whole.

\section{RECOMMENDATIONS}

The current study has effectively examined the aspect of employee's innovation capacity with help of HRIS usage and knowledge-sharing behaviour. The role of organizational citizenship behaviour has been also included as a moderation variable. The target population of this study was the firms (banks) of Karachi, Pakistan. The study has collected data via a quantitative approach using purposive sampling that was analyzed with PLS-SEM using Smart-PLS 3.2.8.

The first result was between HRIS usage and employee's innovation capacity has been found positive and significant. This result proposed that when an organization increases their HRIS technology it eventually leads up to provide benefit towards employees. These benefits can be in the shape of properly making the schedule, delivering tasks up to data, enhancement in performance and innovation capacity of employees. The second result was between knowledgesharing behaviour (KSB) and employee's innovation capacity that is positive and insignificant. This result proposed that when KSB increased and increased the amount of knowledge in 
employees then it might have made employees somewhat relax or less efficient and this might be the reason for the insignificant relation. The third result between organizational citizenship behaviour (OCB) and employee's innovation capacity has been positive and significant. This result has shown that when the employees show adaptive behaviour that provides effective advantages to the organization in an uncertain environment then it increases their innovation capacity. The major advantage is to work on the same page for increasing the organization performance increases their innovation capacity. The fourth result shows that OCB has a positive and significant moderation between HRIS usage and employee's innovation capacity. This result shows that when the HRIS meets with the adaptive behaviour of employees that aims towards providing benefits to the organization then it also increases the innovation capacity of employees. The fifth result shows that OCB has a positive and significant moderation between KSB and employee's innovation capacity. This result reveals that between KSB and innovation the presence of OCB helps in this way that by sharing knowledge the employees can significantly relate or communicate with each other and eventually increases their innovation capacity.

Furthermore, one more relationship has been discussed that has been among organizational citizenship behaviours and employee innovation capacity. Managers are recommended to see the demands of the organization along with the current competitive environment where they are supposed to give the space to their employees and ask them to do the task according to the new market tactics. Furthermore, managers can provide an environment where the task can flourish easily. It is considered as the most important ground for the employees through which social connections can be built that can directly influence job performance. However, productivity increases when space is given to the employees. Managers are recommended here to motivate them to empower the workforce ground where motivation will boost and the productivity will increase which will increase innovativeness in work tasks.

\section{RESEARCH IMPLICATIONS}

In the current study, the relationship between HRIS usage and employee innovation capacity has been discussed and marked as positive. On this ground, managers are recommended here to focus on the HRIS storage where the managers can easily track the performance of the employees. It makes it easier for the managers of the organizations to track all the data and information along with full access to the employee information. The data that has been collected by the organization can easily be handled by the software. However, this employee's innovation capacity is also affected at a larger ratio. Managers can give space to their employees to increase productivity 
while by this ground employee will be more satisfied where he or she will be allowed to have work by their ways by searching new ideas to work on. When managers will use the platform of HRIS usage keenly and wisely, the employee innovation capacity will be handled so well. The data or information will be safe easily and it will help further the organization to achieve the goals. By this, an organization can easily get benefits of improved productivity along with this turnover will be decrease and profitability will increase. Somehow, by this, the new partnership can be signed, and new things can easily build up.

\section{FUTURE RESEARCH RECOMMENDATIONS}

Future researchers are recommended to use these recommendations to overcome the current research limitations. The qualitative approach is recommended so that it can provide more indepth data and results. The use of a longitudinal time horizon is also advisedso that the data can be collected in a more stretched time. Future researches are recommended to conduct this study on different industries and countries for different outcomes. Future researches are also recommended to use other variables like employee motivation, self-efficacy, employee satisfaction, and job performance as well. The use of causal design is also recommended to examine the causation between variables.

\section{Acknowledgement:}

The authors acknowledge that the manuscript is an original work and there was no financial or non-financial support taken for this study.

\section{Author(s) Contribution:}

All authors have equally contributed to this article. 


\section{REFERENCES}

Abubakar, A. M., Elrehail, H., Alatailat, M. A., \& Elçi, A. (2019). Knowledge management, decision-making style and organizational performance. Journal of Innovation \& Knowledge, 4(2), 104-114. https://doi.org/10.1016/j.jik.2017.07.003

Afsar, B., Masood, M., \& Umrani, W. A. (2019). The role of job crafting and knowledge sharing on the effect of transformational leadership on innovative work behaviour. Personnel Review. https://doi.org/10.1108/PR-04-2018-0133

Agostini, L., Nosella, A., \& Filippini, R. (2017). Does intellectual capital allow improving innovation performance? A quantitative analysis in the SME context. Journal of Intellectual Capital. https://doi.org/10.1108/JIC-05-2016-0056

Ahmer, Z. (2013). Adoption of human resource information systems innovation in Pakistani organizations. Journal of Quality and Technology Management, 9(2), 22-50.

Akio, T. (2005). The critical assessment of the resource-based view of strategic management: the source of heterogeneity of the firm. Ritsumeikan international affairs, 3(1), 125-150.

Allameh, S. M., Hosseini, S. H., Samadi, A., \& Darikandeh, A. (2017). The relationship between intangible organisational capitals, knowledge management, and organisational learning. International Journal of Knowledge-Based Development, 8(3), 249-270 and organizational citizenship behaviours. Asia pacific journal of information systems, 16(3), 29-47. https://doi.org/10.1504/IJKBD.2017.086416

Asurakkody, T. A., \& Hee, S. (2020). Effects of knowledge sharing behaviour on innovative work behaviour among nursing students: Mediating role of self-leadership. International Journal of Africa Nursing Sciences, 100190. https://doi.org/10.1016/j.ijans.2020.100190

Azam, M. K., \& Waraich, U. (2019). Factors Effecting Employee Turnover: A Study to Understand Organizational Retention Strategies. Journal of Entrepreneurship, Management, and Innovation, 1(1), 51-61. https://doi.org/10.52633/jemi.v1i1.42

Bacq, S., \& Eddleston, K. A. (2018). A resource-based view of social entrepreneurship: How stewardship culture benefits scale of social impact. Journal of Business Ethics, 152(3), 589-611.

Bantha, T., \& Sahni, S. P. (2021). The relation of servant leadership with followers' organizational citizenship behaviour (OCB): mediating role of generalized self-efficacy (GSE) and organization-based self-esteem (OBSE). Industrial and Commercial Training. https://doi.org/10.1108/ICT-02-2020-0024

Barišić, A. F., Pejić Bach, M., \& Miloloža, I. (2018). Human resource information systems: Transactional and strategic paradigm. Paper presented at the Proceedings of the ENTRENOVA-ENTerprise REsearch InNOVAtion Conference, Split, Croatia, 6-8 September 2018. http://dx.doi.org/10.2139/ssrn.3283100 
Barney, J. B. (1995). Looking inside for competitive advantage. Academy of Management Perspectives, 9(4), 49-61. https://doi.org/10.5465/ame.1995.9512032192

Bayraktaroğlu, S., \& Atay, E. (2016). Strategic human resource management. In: Istanbul: Beta Publishing.

Bogler, R., \& Somech, A. (2019). Psychological capital, team resource and organizational citizenship behaviour. The Journal of Psychology, 153(8), 784-802. https://doi.org/10.1080/00223980.2019.1614515

Bondarouk, T., Parry, E., \& Furtmueller, E. (2017). Electronic HRM: Four decades of research on adoption and consequences. The International Journal of Human Resource Management, 28(1), 98-131. https://doi.org/10.1080/09585192.2016.1245672

Brandon-Jones, A., \& Kauppi, K. (2018). Examining the antecedents of the technology acceptance model within e-procurement. International Journal of Operations \& Production Management. https://doi.org/10.1108/IJOPM-06-2015-0346

Bromiley, P., \& Rau, D. (2016). Operations management and the resource based view:Another view. Journal of Operations Management, 41, 95-106. https://doi.org/10.1016/j.jom.2015.11.003

Constance, N. W., Zawawi, D., Karim, J., Mansor, S. A., Sentosa, I., \& Yusuf, R. N. R. (2019). Supervisory justice, organizational citizenship behaviour, and innovative behaviour: The mediating role of tacit knowledge sharing among nurses. http://dx.doi.org/10.6007/IJAREMS/v8-i4/6703

Flick, U. (2015). Introducing research methodology: A beginner's guide to doing a research project: Sage.

Fornell, C., \& Larcker, D. F. (1981). Structural equation models with unobservable variables and measurement error: Algebra and statistics. Journal of marketing research, 18(3), 382-388. https://doi.org/10.1177/002224378101800313

Gibson, C. B., Gibson, S. C., \& Webster, Q. (2021). Expanding our resource: Including community in the resource-based view of the firm. Journal of Management, 0149206320987289. https://doi.org/10.1177/0149206320987289

Hadad, S. (2017). Knowledge economy: Characteristics and dimensions. Management Dynamics in the Knowledge Economy, 5(2), 203-225.

Hadi, P., \& Saerang, D. P. (2020). The influence of transformational leadership and employee integrity through organizational citizenship behaviour (OCB) on employee innovation in regency/city inspectorates. Journal of Business and Behavioural Entrepreneurship, 4(1), 81-90. https://doi.org/10.21009/JOBBE.004.1.06

Hair, J. F., Hult, G. T. M., Ringle, C., \& Sarstedt, M. (2016). A primer on partial least squares structural equation modeling (PLS-SEM): Sage Publications. 
https://doi.org/10.1080/1743727X.2015.1005806

Hair, J. F., Ringle, C. M., \& Sarstedt, M. (2011). Pls-sem: Indeed a silver bullet. Journal of Marketing Theory and Practice, 19(2), 139-152. https://doi.org/10.2753/MTP10696679190202

Hair, J. F., Sarstedt, M., Hopkins, L., \& Kuppelwieser, V. G. (2014). Partial least squares structural equation modeling (pls-sem) An emerging tool in business research. European Business Review, 26(2), 106-121. https://doi.org/10.1108/EBR-10-2013-0128

Halisah, A., Jayasingam, S., Ramayah, T., \& Popa, S. (2021). Social dilemmas in knowledge sharing: an examination of the interplay between knowledge sharing culture and performance climate. Journal of Knowledge Management. https://doi.org/10.1108/JKM08-2020-0631

Harjanti, D., \& Noerchoidah, N. (2017). The effect of social capital and knowledge sharing on innovation capability. Jurnal Manajemen dan Kewirausahaan, 19(2), 72-78. https://doi.org/10.9744/jmk.19.2.72-78

Kavanagh, M. J., \& Johnson, R. D. (2017). Human resource information systems: Basics, applications, and future directions: Sage Publications.

Kaygusuz, İ. (2016). The impact of HRIS usage on organizational efficiency and employee performance.

Khan, N. U., Saufi, R. A., \& Ahmed, A. (2021). Antecedents of organizational citizenship behaviour towards the environment in manufacturing organizations: using a structural equation modeling approach. Business Process Management Journal. https://doi.org/10.1108/BPMJ-02-2021-0102

Khashman, I. M. A., \& Khashman, A. M. (2016). The impact of human resource information system (HRIS) applications on organizational performance (efficiency and effectiveness) in Jordanian private hospitals. Hospitals, 8(3).

Leary, M. R. (2004). Introduction to behavioural research methods: Pearson Education New Zealand.

Liao, S.-H., Fei, W.-C., \& Chen, C.-C. (2007). Knowledge sharing, absorptive capacity, and innovation capability: An empirical study of Taiwan's knowledge-intensive industries. Journal of information science, 33(3), 340-359. https://doi.org/10.1177/0165551506070739

Magableh, A. N., \& Al-Tarawneh, J. T. (2021). The Effect of Information Systems for Human Resource on the Capability of Individual Innovation in Jordanian Companies: A Conceptual Review. The Big Data-Driven Digital Economy: Artificial and Computational Intelligence, 393-413. https://doi: 10.1007/978-3-030-73057-4_30

Matimbwa, H., \& Masue, O. S. (2019). Usage and challenges of human resource information 
system in the Tanzanian public organizations. Journal of Human ResourceManagement, 7(4), 131-137. doi: 10.11648/j.jhrm.20190704.17

Mauro, T. G., \& Borges-Andrade, J. E. (2020). Human resource system as innovation for organisations. Innovation \& Management Review. https://doi.org/10.1108/INMR-032019-0037

Moussa, N. B., \& El Arbi, R. (2020). The impact of Human Resource Information Systems on individual innovation capability in Tunisian companies: The moderating role of affective commitment. European Research on Management and Business Economics, 26(1), 1825. https://doi.org/10.1016/j.iedeen.2019.12.001

Naeem, A., Mirza, N. H., Ayyub, R. M., \& Lodhi, R. N. (2019). HRM practices and faculty's knowledge sharing behaviour: Mediation of affective commitment and affect-based trust. Studies in Higher Education, 44(3), 499-512. https://doi.org/10.1080/03075079.2017.1378635

Neuman, W. L. (2013). Social research methods: Qualitative and quantitative approaches: Pearson education.

Newman, A., Schwarz, G., Cooper, B., \& Sendjaya, S. (2017). How servant leadership influences organizational citizenship behaviour: The roles of IMX, empowerment, and proactive personality. Journal of Business Ethics, 145(1), 49-62.

Nguyen, T.-M., \& Malik, A. (2020). Cognitive processes, rewards and online knowledge sharing behaviour: The moderating effect of organisational innovation. Journal of Knowledge Management. https://doi.org/10.1108/JKM-12-2019-0742

Ologbo, A. C., Nor, K. M., \& Okyere-Kwakye, E. (2015). The influence of knowledge sharing on employee innovation capabilities. International Journal of Human Resource Studies, 5(3), 102-110. http://dx.doi.org/10.5296/ ijhrs.v5i3.8210

Organ, D. W. (1988). Organizational citizenship behaviour: The good soldier syndrome: Lexington Books/DC Heath and Com.

Qamari, I. N., Dewayani, J., \& Ferdinand, A. T. (2019). Strategic human resource roles and knowledge sharing: How do enhancing organizational innovation? Calitatea, 20(168), 86-92.

Rahmat Ullah Shah, S., \& Mahmood, K. (2013). Knowledge-sharing behaviour in the dairy sector of Pakistan. Library Philosophy and Practice (917). Research Studies, 21, 389402.

Riana, I. G., Rihayana, I. G., Ratih, K., \& Dewi, I. A. (2019). Creating innovation through knowledge sharing and absorptive capacity. Polish Journal of Management Studies, 19. Ritsumeikan international affairs, 3(1), 125-150.

Razzak, F., Shaikh, S., \& Siddiqui, A. (2019). Exploring Effects of Learning Styles on Learning 
Outcomes. New Horizons (1992-4399), 13(1).

Runyan, R. C., Huddleston, P., \& Swinney, J. (2006). Entrepreneurial orientation and social capital as small firm strategies: A study of gender differences from a resource-based view. The International Entrepreneurship and Management Journal, 2(4), 455.

Saripin, M. S. B., \& Kassim, E. S. (2019). Factors of innovative behaviour in Malaysia.

Scupola, A., \& Pollich, Z. (2019). Adoption of human resource information systems in Danish SMEs. ITAIS and MCIS 2019-Digital Transformation and Social Innovation.

Siddiqui, S. H., Rasheed, R., Nawaz, S., \& Abbas, M. (2019). Knowledge sharing andinnovation capabilities: The moderating role of organizational learning. Pakistan Journal of Commerce and Social Sciences (PJCSS), 13(2), 455-486.

Suwanti, S., Udin, U., \& Widodo, W. (2018). Person-organization fit, person-job fit, and innovative work behaviour: The role of organizational citizenship behaviour. European

Tabachnick, B. G., Fidell, L. S., \& Ullman, J. B. (2007). Using multivariate statistics (Vol.

Valcik, N. A., Sabharwal, M., \& Benavides, T. J. (2021). Existing Research on HRIS in Public Organizations. In Human Resource Information Systems (pp. 33-45). Springer, Cham. https://doi: 10.1007/978-3-030-75111-1_3

Yan, L., \& Yan, J. (2013). Leadership, organizational citizenship behaviour, and innovation in small business: An empirical study. Journal of Small Business \& Entrepreneurship, 26(2), 183-199. https://doi.org/10.1080/08276331.2013.771863

Yang, Z., Nguyen, V. T., \& Le, P. B. (2018). Knowledge sharing serves as a mediator between collaborative culture and innovation capability: An empirical research. Journal of Business \& Industrial Marketing. https://doi.org/10.1108/JBIM-10-2017-0245

Yoon, C. (2009). The effects of organizational citizenship behaviours on ERP system success. Computers in Human Behaviour, 25(2), 421-428. https://doi.org/10.1016/j.chb.2008.10.004

Zhang, L., Wang, H., Cao, X., Wang, X., \& Zhao, K. (2012). Knowledge management component in managing human resource for enterprises. Information Technology and Management, 13(4), 341-349. https://doi.org/10.1007/s10799-012-0127-8 